Check for updates

Cite this: RSC Adv., 2017, 7, 43052

Received 17th May 2017

Accepted 30th August 2017

DOI: 10.1039/c7ra05553f

rsc.li/rsc-advances

\section{A correlation between the degradability of poly(butylene succinate)-based copolyesters and catalytic behavior with Candida antarctica lipase B}

\author{
Min Zhang, (D) *ab Xiao-ning Ma, (D) a Cheng-tao Li, (DD ${ }^{b}$ Dong Zhao, ${ }^{a}$ Yong-lei Xing ${ }^{c}$ \\ and Jian-hui Qiu ${ }^{d}$
}

Polyesters can be degraded by Candida antarctica lipase B (CALB). Herein, the poly(butylene succinate) (PBS) based random copolyesters of a third monomer 1,3-propanediol (PDO), 1,5-pentanediol (PeD) and 1,6-hexanediol (HDO) were successfully synthesized using a melt polycondensation method, and the action of CALB in the buffer solution for 5 days was studied to analyze the degradation mechanism of the copolyesters with high number average molecular weight. Molecular simulations were employed to investigate the binding free energy and interaction between copolyesters and enzymes during degradation. In addition, the weight loss rate and liquid chromatography-mass spectrometry (LC-MS) were used to evaluate the degradability of the synthesized materials. The results showed that the degradation percentage of copolyesters modified with a third monomer were higher than that of pure PBS, with the order of the degradation performance being $\mathrm{P}(\mathrm{BS}-\mathrm{CO}-\mathrm{PeD})>\mathrm{P}(\mathrm{BS}-\mathrm{CO}-\mathrm{HDO})>\mathrm{P}(\mathrm{BS}-\mathrm{CO}-$ $\mathrm{PDO})>$ PBS. Notably, the maximum value, achieved in P(BS-co-20\%PeD), was $85 \%$. Molecular dynamics and docking simulations revealed the changes in CALB amino acid residues and binding free energy, demonstrating that both $\mathrm{P}(\mathrm{BS}-\mathrm{CO}-\mathrm{PeD})$ and $\mathrm{P}(\mathrm{BS}-\mathrm{CO}-\mathrm{HDO})$ polyesters can interact strongly with CALB, which can explain the enzymatic degradation behavior of the copolyesters from the molecular point of view. This research provides a new perspective in the study of interactions between lipase and polyesters.

\section{Introduction}

Polymer materials have been widely applied in various fields because of their excellent performances. However, the excessive use of polymers has led to major environmental damage due to their resistance to physical aging and biological attack, resulting in tremendous damage to the environment. ${ }^{1,2}$ In order to address these severe problems, new degradable materials with competitive performance properties, i.e., aliphatic polyesters ${ }^{3}$ have been developed as an alternative to non-biodegradable plastics. Poly(butylene succinate) (PBS), obtained by the direct polymerization of succinic acid and butanediol, is one of the most widely used aliphatic polyesters due to its good biodegradability, biocompatibility properties, excellent processing properties and satisfactory mechanical properties. ${ }^{4-7}$ Recently, chain extended multi-block aliphatic polyesters and PBS bionanocomposites ${ }^{\mathbf{8 - 1 0}}$

\footnotetext{
${ }^{a}$ Key Laboratory of Auxiliary Chemistry \& Technology for Chemical Industry, Ministry of Education, Shaanxi University of Science \& Technology, Xi'an 710021, China. E-mail: yanjiushi206@163.com

${ }^{b}$ School of Environmental Science \& Engineering, Shaanxi University of Science \& Technology, Xi'an 710021, China

${ }^{c}$ Electronic Materials Research Laboratory, International Center for Dielectric Research, Xi'an Jiaotong University, Xi'an 710049, China

${ }^{d}$ Akita Prefectural University, Akita 015-0055, Japan
}

have been prepared for a wide range of applications such as food packaging, ${ }^{11,12}$ drug delivery, ${ }^{13}$ biomedical ${ }^{14}$ and engineering materials. ${ }^{15}$ In view of the biodegradability of PBS, much work has been performed to demonstrate the feasibility of the degradation of PBS by bacteria, soil and enzymes. ${ }^{16-20}$

Lipases (EC 3.1.1.3) have been exploited on a large scale as an efficient catalyst for the hydrolysis of the ester bond between alcohol and carboxylic acid in the aqueous media. Candida antarctica lipase B (CALB), serine protease, is a potent biocatalyst for polyester degradation with the crucial advantages of a broad substrate specificity and a stable performance. ${ }^{\mathbf{2 0 2}}$ The sequence and crystal structure of CALB have been determined by Uppenberg, ${ }^{22,23}$ CALB has an $\alpha / \beta$ type and a Ser-His-Asp catalytic triad in the active site that plays a decisive role in catalyzing the substrate. ${ }^{24}$ Due to its high stability, stereoselectivity and strong activity, ${ }^{21,25}$ various studies focus on enantiomeric recognition, the evaluation of the activity and the stability in organic solvents. ${ }^{26-29}$ However, to the best of our knowledge, few works have been devoted to the polymers degradation by CALB. Therefore, the present study investigates the degradation mechanism of polyesters by CALB.

It is well known that the degradation of aliphatic polyesters is affected by the chemical structure of the repeat unit, which can further influence their flexibility, crystallinity, thermal properties and morphological properties. ${ }^{\mathbf{1 5}, 30}$ To date, various 
studies has made the degradation controllable by developing various PBS copolymers or their composites. ${ }^{31,32}$ Indeed, the synthesis of PBS-based copolymers can efficiently alter its chemical structure and tune its degradation behavior. Significantly, reports on the effect of the structure of PBS copolymers with different chain lengths on their degradation by CALB remain scarce. In the present paper, we synthesized PBS and there of its copolyesters modified by the monomers of different chain lengths to study the degradation performance of copolyesters and the catalytic behavior of CALB, as well as to understand the degradation mechanism.

In this regard, the molecular simulation is an essential way to figure out the details of ligand-protein complex. ${ }^{33,34}$ Combining molecular dynamics and molecular docking, ${ }^{35,36}$ we aimed to understand the conformational changes of CALB in water and the positions of its ligands. Simultaneously, we obtained the binding free energy of the ligand-receptor, as well as the information about the active site pocket. We reasonably designed the docking model used to study the recognition of the substrate by CALB and the substrate conformational changes, the interaction around the active pocket were also obtained. This research provides theoretical guidance of the degradation of large molecular weight polyesters degraded by CALB at the molecular level.

\section{Experimental}

\section{Materials}

The PBS homopolymer and $\mathrm{P}(\mathrm{BS}-\mathrm{co}-\mathrm{PDO}), \mathrm{P}(\mathrm{BS}-\mathrm{co}-\mathrm{PeD})$, and $\mathrm{P}(\mathrm{BS}-\mathrm{co}$-HDO) copolyesters were synthesized from succinic acid and diols. 1,4-Succinic acid (S) and 1,4-butanediol (BDO) were obtained from Sinopharm Chemical Reagent Co. Ltd. 1,3-Propanediol (PDO), 1,5-pentanediol (PeD), and 1,6-hexanediol (HDO) were purchased from Alfa Aesar Chemical Reagent Co. Ltd., CALB was purchased from Novozymes (China) Investment Co. Ltd. All reagents in this study were of analytical grade, and were used without further purification.

\section{Experimental procedures}

Synthesis of polyester. Polyesters were prepared by the melt polycondensation method in a three-necked flask, including two steps of esterfication and polycondensation with $\mathrm{Ti}(\mathrm{OBu})_{4}$ as the catalyst. The molar ratio of $S$ to diols was $1: 1.1$, and the feed molar ratio of PDO, PeD, and HDO in the copolyesters were $0 \%, 5 \%, 10 \%, 15 \%$, and $20 \%$, respectively. The reactor was filled with nitrogen to protect the reaction from oxidation and then the reaction mixture was heated to $180^{\circ} \mathrm{C}$ to dehydrate until the theoretical amount of $\mathrm{H}_{2} \mathrm{O}$ was collected. The polycondensation process was carried out at $230{ }^{\circ} \mathrm{C}$ under a vacuum of $5.5 \mathrm{~Pa}$ for approximately $2 \mathrm{~h}$, and then washed with ethanol for several times and dried under the vacuum for further use.

Measurements. The NMR spectra of copolyesters were recorded on a Bruker ADVANCE III 400 instrument (Bruker Corporation, Germany), at $400 \mathrm{MHz}$. All samples were dissolved in a $\mathrm{CDCl}_{3}$ solution and scanned 32 times for each sample. The chemical shifts of ${ }^{1} \mathrm{H}$ NMR were reported in ppm with the reference of tetramethylsilane (TMS).

Gel permeation chromatography was performed by P230 GPC (Dalian Yilite Analytical Instruments, China) equipped with a refractive index detector Shodex RI-201H to determine the molecular weight and molecular weight distribution of polyesters. Chloroform was used as the mobile phase at a flow rate of $1.0 \mathrm{~mL} \mathrm{~min}{ }^{-1}$, and $20 \mu \mathrm{L}$ of a $1.0 \mathrm{w} / \mathrm{v} \%$ solution was injected in all analyses. The column temperature was maintained at $40{ }^{\circ} \mathrm{C}$, and polystyrene standards were obtained from Shodex to be a calibration curve for the number-average $\left(M_{\mathrm{n}}\right)$ and weight-average molecular weights $\left(M_{\mathrm{w}}\right)$.

The thermal stabilities of the polyesters were studied by thermogravimetric analysis (TGA, Q500, TA Instruments) in a nitrogen atmosphere. All samples $(\sim 5 \mathrm{mg})$ were heated from room temperature to $500{ }^{\circ} \mathrm{C}$ at a heating rate of $10{ }^{\circ} \mathrm{C} \mathrm{min}^{-1}$.

The basic thermal parameters were determined by differential scanning calorimetry (DSC, Q500, TA Instruments). A specimen of approximately 3-5 $\mathrm{mg}$ was encapsulated in aluminium pans under a high-purity nitrogen atmosphere. Samples were heated to $160{ }^{\circ} \mathrm{C}$ at a rate of $10{ }^{\circ} \mathrm{C} \mathrm{min}{ }^{-1}$ for $5 \mathrm{~min}$ to eliminate their thermal history, and cooled to $-60^{\circ} \mathrm{C}$ at a rate of $5{ }^{\circ} \mathrm{C} \mathrm{min}{ }^{-1}$, and finally, reheated to $160{ }^{\circ} \mathrm{C}$ at a rate of $10{ }^{\circ} \mathrm{C} \mathrm{min}^{-1}$.

Wide-angle X-ray diffraction (WAXD) analysis was performed by Rigaku $\mathrm{D} / \mathrm{Max}-3 \mathrm{c}$ with $\mathrm{Cu} \mathrm{K} \alpha$ radiation. The scanning range was from $5^{\circ}$ to $40^{\circ}$ at a rate of $6^{\circ} \mathrm{min}^{-1}$ with a step of $0.02^{\circ}$.

The chromatographic analysis system consisted of a Waters, WASAD2/E2695* (Waters, Technology, Co. Ltd.) coupled to a triple quadrupole mass spectrometer using an electrospray ionization source (ESI) to identify the degradation products. The scan range was from 100 to $1200 \mathrm{~m} / \mathrm{z}$, with a capillary voltage of $4000 \mathrm{~V}$, and nitrogen as the auxiliary gas.

Enzymatic degradation. Polyesters films were prepared by melt-pressing at $130{ }^{\circ} \mathrm{C}$, and then cut into $15 \times 25 \times 0.4 \mathrm{~mm}$ in pieces to degrade. These films were incubated in triplicate in separate tubes containing $15 \mathrm{~mL}$ of phosphate buffer solution $\left(\mathrm{pH} 7.20 \pm 0.01,0.1 \mathrm{~mol} \mathrm{~L}^{-1}\right)$ and $0.06 \mathrm{~g}$ CALB at $45{ }^{\circ} \mathrm{C}$, meanwhile a control system was run parallel with them without CALB. After $24 \mathrm{~h}$ intervals, the films were removed from the system, and then washed with distilled water and dried under vacuum to constant weight. The degradation process was 5 days long. The weight loss rate was calculated by the following formula $\left(W_{0}-W_{\mathrm{t}}\right) / W_{0} \times 100 \%$, where $W_{0}$ is the weight of the polyester film before degradation, $W_{\mathrm{t}}$ is the residue weight after degradation at the different times.

Molecular dynamic simulation. In order to explore the average protein structure, the molecular dynamics (MD) simulation were performed by YASARA V13.12. ${ }^{37}$ The starting crystal structure of the CALB was obtained from the protein data bank (PDB code:1TCA). In this simulation, the force field was AMBER 03 at $45{ }^{\circ} \mathrm{C}$ and under the constant pressure of $1.0 \times 10^{5} \mathrm{~Pa}$; the temperature and pressure coupling were all done by the Berendsen algorithm. It is worth mentioning that the system $\mathrm{pH}$ was 7.20, including 4000 water molecules as well as $\mathrm{NaCl}$ used to neutralize the system. Long-range electrostatics was evaluated by the particle mesh Ewald method ${ }^{38}$ with a $10 \AA$ cutoff, whereas a $14 \AA$ cut off was also employed to evaluate the 

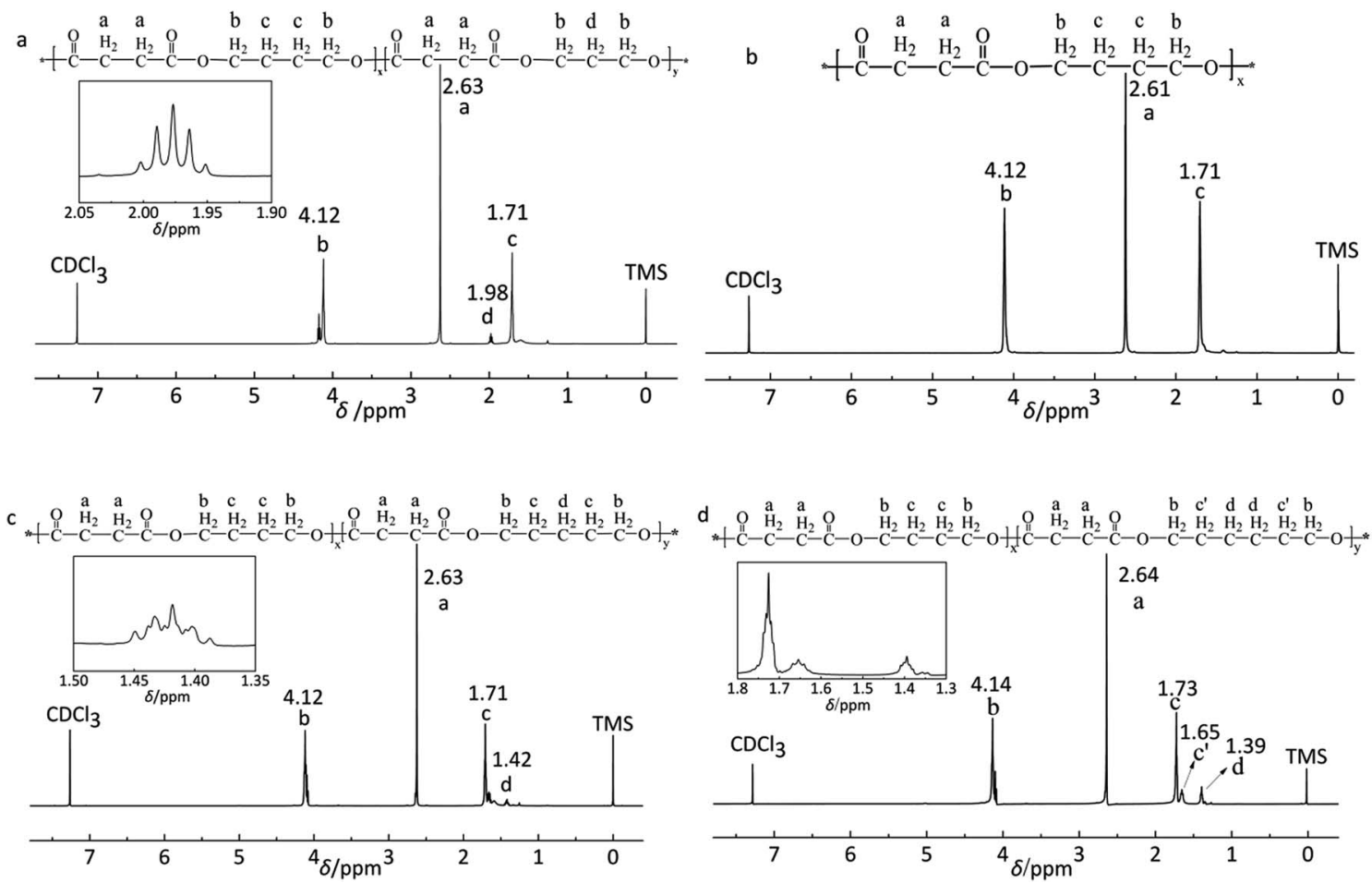

Fig. $1{ }^{1} \mathrm{H}$-NMR spectrum of random copolymers: (a) P(BS-co-15\%PDO), (b) PBS, (c) P(BS-co-15\%PeD), (d) P(BS-co-15\%HDO).

Lennard-Jones potential. The system was minimized for 5000 steps by steepest descent algorithm. The MD simulations were propagated through 2.0 fs time step, and subjected to $100 \mathrm{ps}$ of equilibration with the protein being both fixed and mobile. Notably all the MDs were run for 50 ns using a snapshots and saved every 10 ps for the subsequent analyses.

Molecular docking. Docking was conducted to analyze the optimal conformation during the combination between CALB and substrates. The lipase used for molecular docking was determined by the output of the average structure of the stable stage from MD. Herein, four substrate models, namely PDOSPDO, BSB, PeDSPeD and HDOSHDO were devised to implement docking (see Fig. 1). All the substrates were minimized by ChemOffice v8.0, MM2 force field before the docking analysis. All docking calculations were performed with AutoDock 4.2, AutoGrid 4.2, MGL tools 1.5.6 attached to AutoDock tools, and the Lamarckian genetic algorithm method. ${ }^{39-41}$ The docking box was $60 \times 60 \times 60 \AA$, defined by the alpha carbon of serine in the catalytic triad. For each ligand-receptor combination, 200 docked poses were obtained. According to the scoring function and the best dimensional scale, the lowest binding energy was output to understand the interaction conformation. PyMOL ${ }^{42,43}$ was processed to support the dimensional visualization between the ligand and enzyme.

\section{Results and discussion}

\section{Synthesis and characterization of polyesters}

The polyesters were synthesized through melt polycondensation at varing feed molar ratio of the third monomer to improve the degradation properties of PBS. The typical ${ }^{1} \mathrm{H}$ NMR spectra are shown in Fig. 1. The data concerning copolyesters molecular characterization are reported in Table 1. All the copolyesters and PBS homopolymer were of high molecular weight (Fig. 2). Further, the real compositions of each polyester was determined by ${ }^{1} \mathrm{H}$ NMR, closed to the feed one (see Table 1 ). The peak at 1.98 ppm (d labelled protons) shown in Fig. 1a was attributed to the methylene of PDO. The typical methylene protons resonances of $\mathrm{S}$ at $2.61 \mathrm{ppm}$ (a labelled protons) and at $4.12 \mathrm{ppm}$ (b labelled protons) and $1.71 \mathrm{ppm}$ (c labelled protons)

Table 1 Compositions and molecular weights of resulting polyesters

\begin{tabular}{|c|c|c|c|c|}
\hline Polyester & $F_{\mathrm{PDO} / \mathrm{PeD} / \mathrm{HDO}}{ }^{a}(\mathrm{~mol} \%)$ & $M_{\mathrm{n}}{ }^{b} \mathrm{kDa}$ & $M_{\mathrm{w}}{ }^{c} \mathrm{kDa}$ & $\mathrm{PDI}^{d}$ \\
\hline PBS & 0.0 & 67.5 & 134.3 & 1.99 \\
\hline $\mathrm{P}(\mathrm{BS}-c o-5 \% \mathrm{PDO})$ & 4.8 & 55.9 & 123.0 & 2.20 \\
\hline $\mathrm{P}(\mathrm{BS}-c o-10 \% \mathrm{PDO})$ & 10.0 & 66.0 & 131.6 & 1.99 \\
\hline $\mathrm{P}(\mathrm{BS}-c o-15 \% \mathrm{PDO})$ & 14.5 & 59.3 & 139.4 & 2.35 \\
\hline $\mathrm{P}(\mathrm{BS}-c o-20 \% \mathrm{PDO})$ & 18.6 & 56.1 & 105.2 & 1.87 \\
\hline $\mathrm{P}(\mathrm{BS}-c o-5 \% \mathrm{PeD})$ & 5.0 & 61.8 & 124.6 & 1.97 \\
\hline $\mathrm{P}(\mathrm{BS}-c o-10 \% \mathrm{PeD})$ & 9.7 & 65.2 & 126.1 & 1.94 \\
\hline $\mathrm{P}(\mathrm{BS}-c o-15 \% \mathrm{PeD})$ & 14.8 & 65.9 & 143.9 & 2.18 \\
\hline P(BS-co-20\%PeD) & 19.2 & 71.2 & 132.7 & 1.86 \\
\hline $\mathrm{P}(\mathrm{BS}-c o-5 \% \mathrm{HDO})$ & 5.0 & 59.1 & 138.1 & 2.34 \\
\hline $\mathrm{P}(\mathrm{BS}-\mathrm{co}-10 \% \mathrm{HDO})$ & 9.8 & 59.6 & 128.4 & 2.15 \\
\hline $\mathrm{P}(\mathrm{BS}-c o-15 \% \mathrm{HDO})$ & 14.5 & 70.5 & 144.8 & 2.05 \\
\hline $\mathrm{P}(\mathrm{BS}-c o-20 \% \mathrm{HDO})$ & 20.0 & 71.4 & 151.1 & 2.11 \\
\hline
\end{tabular}

${ }^{a}$ Compositions of polymers determined by ${ }^{1} \mathrm{H}$ NMR. ${ }^{b}$ Number average molecular weight measured by GPC analysis. ${ }^{c}$ Weight average molecular weight measured by GPC analysis. ${ }^{d}$ Polydispersity index measured by GPC analysis. 


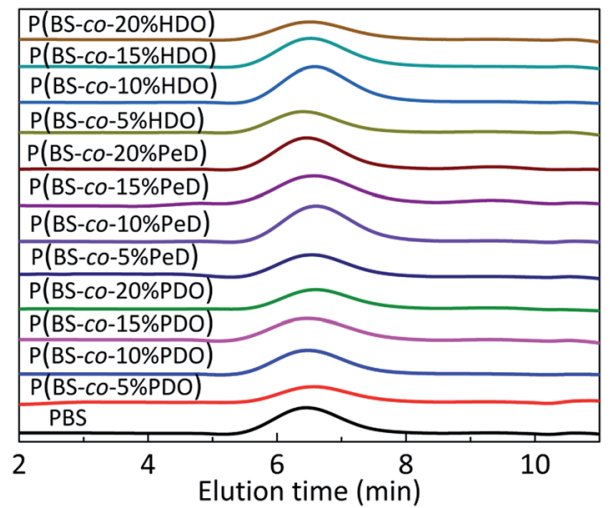

Fig. 2 GPC diagrams of polyesters. Stack plot of GPC traces of PBS and their polyesters. RI signal is reported as a function of elution time (min).

from BDO in Fig. 1b were the typical absorption peaks of PBS. Two peaks at $1.71 \mathrm{ppm}$ (c labelled protons) and at $1.42 \mathrm{ppm}$ (d labelled protons) were assigned to the methylene of PeD in Fig. 1c. The chemical shifts at $1.65 \mathrm{ppm}$ ( $\mathrm{c}^{\prime}$ labelled protons) and $1.39 \mathrm{ppm}$ (d labelled protons) were corresponded to the methylene of HDO (Fig. 1d). The ${ }^{1} \mathrm{H}$ NMR spectra indicated that the polyesters obtained were the expected products.

\section{Enzymatic hydrolysis of polyesters}

Since the degradability of copolyesters was different due to their various structures, the weight loss rate of the different polyesters in the presence of CALB was studied in an aqueous medium shown in Fig. 3. Obviously, it was found that all three copolyesters with the third monomer showed a higher mass loss than that of PBS, and the values increased as the amount of the third monomer increased. Overall, the $\mathrm{P}(\mathrm{BS}-\mathrm{co}-20 \% \mathrm{PeD})$ polyester had the maximum weight loss rate, which reached $85 \%$ in 5 days, followed by $\mathrm{P}(\mathrm{BS}-\mathrm{co}-20 \% \mathrm{HDO})$, reaching $70 \%$. P(BS-co$20 \%$ PDO) had a minimum value of $23 \%$ after 5 days. Significantly, the weight loss of neat PBS was only about $2 \%$.

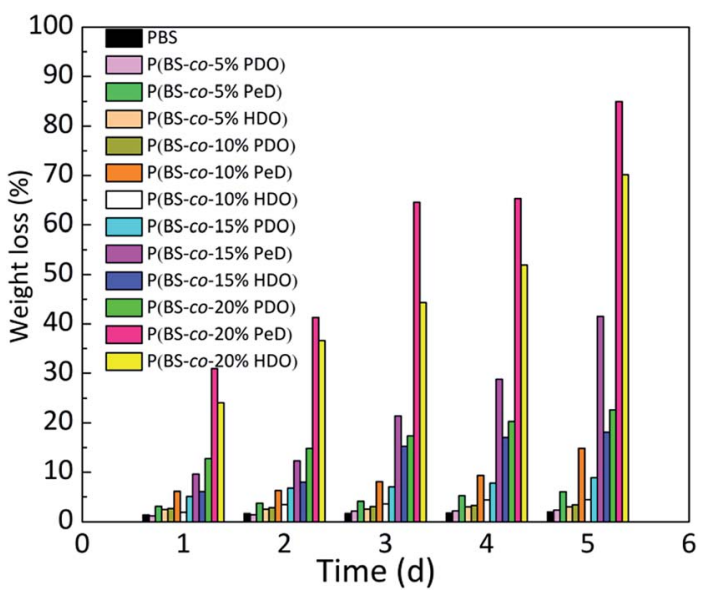

Fig. 3 Weight loss rates of the copolyesters with different components.
It was suspected that the neat spiral chain structure of PBS would break in the presence of the third monomer due to a decrease in the degree of crystallinity, thus offering more free segments for CALB to attack. Nevertheless, when PeD and HDO were introduced, the chain was considerably more flexible than that of PBS, and beneficial for the combination of the enzyme and substrates, and resulting in an accelerated degradation of polyesters based on this point. There will be a more in-depth discussion in next section. It's well-known that the degradation rate is affected by many factors. For example, compared with $\mathrm{P}(\mathrm{BS}-c o-\mathrm{PeD})$, the ester bond density of $\mathrm{P}(\mathrm{BS}-c o-\mathrm{HDO})$ was lower with the same molar fraction, because the former could afford more ester bonds to CALB, enhancing the affinity to enzyme. The more details of this phenomenon would be studied by molecular simulation.

\section{Thermal properties and crystallization ability}

DSC was utilized to evaluate the thermal properties of copolyesters. The thermal parameters are listed in Table 2, and the second heating curves and cooling curves are shown in Fig. 4. As compared with the melting temperature $\left(T_{\mathrm{m}}, 108.68{ }^{\circ} \mathrm{C}\right)$, melting enthalpy $\left(\Delta H_{\mathrm{m}}, 58.64\right)$ and crystallinity $\left(X_{\mathrm{c}-\mathrm{DSC}}, 53.06\right)$ of PBS homopolymer, the $T_{\mathrm{m}}, \Delta H_{\mathrm{m}}$ and $X_{\text {c-DSC }}$ values of copolyesters decreased with the third monomer increased. This may be due to the reduction of the third monomer decreased the chain regularity and then the imperfect crystals appeared, resulting in a decrease in crystallization temperature $\left(T_{\mathrm{c}}\right)$ and crystallization enthalpy $\left(\Delta H_{\mathrm{c}}\right)$. WAXD measurements were performed to analyze the crystalline performance of the copolyesters, as shown in Fig. 5. The three main diffraction peaks were located at $19.6^{\circ}, 21.9^{\circ}, 22.8^{\circ}$, corresponding to the (202), (021) and (110) planes of the $\alpha$-crystal form. In addition, the copolyesters exhibited similar diffraction peaks, indicating that the copolyesters had the same crystal phase. It can be seen that the diffraction peaks became less intense as the third monomer increased, revealing that the copolyesters had a lower crystallinity. Among these copolyesters, $\mathrm{P}(\mathrm{BS}-\mathrm{co}-\mathrm{PeD})$ had the lowest $X_{\mathrm{c}}$, followed by $\mathrm{P}(\mathrm{BS}-\mathrm{c} o-\mathrm{HDO})$, thus $\mathrm{P}(\mathrm{BS}-\mathrm{co}-\mathrm{PeD})$ had the excellent degradability. It well known that the enzyme is more susceptible to degrade the amorphous region. $\mathrm{P}(\mathrm{BS}-c o-\mathrm{PeD})$ could supply more amorphous with CALB to attack first.

The thermal stability of the copolyesters were determined by TGA. Fig. 6 shows the TGA curves of P(BS-co-PDO), P(BS-co-PeD) and $\mathrm{P}(\mathrm{BS}-\mathrm{co}-\mathrm{HDO})$. Overall, copolyesters had similar profiles and weight loss in a single main decomposition process in the range of $280-420{ }^{\circ} \mathrm{C}$, and the decomposition temperatures of PBS homopolymer and its derivatives were above $300{ }^{\circ} \mathrm{C}$ at $5 \%$ weight loss, illustrating that the copolyesters had adequate thermal stability. However, the decomposition temperatures $T_{\mathrm{d}-5 \%}$ and $T_{\mathrm{d}-\max }$ of all the PBS-based copolyesters were lower than that of the pure PBS, indicating that the presence of modifying monomers slightly decreased thermal stability of copolyesters. This phenomenon is attributed to the introduction of the third component leading to the disruption of the regularity and symmetry of the chain segment of polyesters, and particularly of the spiral structure of PBS. On the other hand, 
Table 2 Thermal parameters of polyesters determined by TGA and DSC

\begin{tabular}{|c|c|c|c|c|c|c|c|c|}
\hline Samples & $T_{\mathrm{d}-5 \%}{ }^{a}\left({ }^{\circ} \mathrm{C}\right)$ & $T_{\mathrm{d}-\max }^{b}\left({ }^{\circ} \mathrm{C}\right)$ & $T_{\mathrm{c}}^{c}\left({ }^{\circ} \mathrm{C}\right)$ & $\Delta H_{\mathrm{c}}^{c}\left(\mathrm{~J} \mathrm{~g}^{-1}\right)$ & $T_{\mathrm{m}}{ }^{d}\left({ }^{\circ} \mathrm{C}\right)$ & $\Delta H_{\mathrm{m}}{ }^{d}\left(\mathrm{~J} \mathrm{~g}^{-1}\right)$ & $X_{\mathrm{c}-\mathrm{DSC}}{ }^{e}(\%)$ & $X_{\mathrm{c}-\mathrm{XRD}}{ }^{f}(\%)$ \\
\hline PBS & 324.97 & 389.23 & 83.26 & 65.55 & 108.68 & 58.64 & 53.06 & 54.60 \\
\hline $\mathrm{P}(\mathrm{BS}-c o-5 \% \mathrm{PDO})$ & 320.96 & 389.00 & 72.08 & 57.91 & 96.81 & 49.97 & 45.22 & 47.15 \\
\hline $\mathrm{P}(\mathrm{BS}-\mathrm{co}-15 \% \mathrm{PDO})$ & 317.16 & 378.76 & 73.16 & 58.46 & 95.50 & 47.19 & 42.71 & 41.77 \\
\hline $\mathrm{P}(\mathrm{BS}-\mathrm{co}-20 \% \mathrm{PDO})$ & 324.99 & 387.83 & 67.88 & 55.72 & 90.75 & 45.66 & 41.32 & 40.58 \\
\hline $\mathrm{P}(\mathrm{BS}-c o-5 \% \mathrm{PeD})$ & 317.95 & 386.00 & 80.97 & 56.48 & 102.55 & 47.37 & 42.87 & 42.99 \\
\hline $\mathrm{P}(\mathrm{BS}-c o-20 \% \mathrm{PeD})$ & 327.28 & 390.75 & 63.12 & 44.06 & 88.67 & 34.46 & 31.19 & 30.56 \\
\hline $\mathrm{P}(\mathrm{BS}-c o-5 \% \mathrm{HDO})$ & 321.99 & 389.10 & 77.88 & 60.05 & 103.42 & 52.25 & 47.28 & 44.25 \\
\hline $\mathrm{P}(\mathrm{BS}-\mathrm{co}-10 \% \mathrm{HDO})$ & 314.42 & 389.18 & 74.52 & 50.18 & 97.92 & 44.47 & 40.24 & 39.80 \\
\hline $\mathrm{P}(\mathrm{BS}-c o-15 \% \mathrm{HDO})$ & 328.74 & 392.00 & 65.60 & 49.45 & 92.31 & 43.64 & 39.49 & 38.18 \\
\hline P(BS-co-20\%HDO) & 323.28 & 388.93 & 61.48 & 49.05 & 86.35 & 41.10 & 37.19 & 35.69 \\
\hline
\end{tabular}

${ }^{a}$ Decomposition temperature of copolyesters at weight loss of $5 \% .{ }^{b}$ Decomposition temperature of copolyesters at the maximum weight loss. ${ }^{c}$ Determined by the cooling scan from the melt at $5{ }^{\circ} \mathrm{C} \min ^{-1} .{ }^{d}$ Determined by the 2nd heating scan at $10^{\circ} \mathrm{C}$ min ${ }^{-1}$. ${ }^{e}$ The crystallinity degree $X_{\text {c-DSC }}$ of polyesters were calculated by dividing the obtained $\Delta H_{\mathrm{m}}$ from the second heating trace by the theoretical value $\left(110.5 \mathrm{~J} \mathrm{~g}^{-1}\right)$ for a $100 \%$ crystalline PBS. $X_{\mathrm{c}}=\Delta H_{\mathrm{m}} / \Delta H_{\mathrm{m}}^{0}, \Delta H_{\mathrm{m}}^{0}=110.5 \mathrm{~J} \mathrm{~g}^{-1} \cdot{ }^{f}$ The crystallinity degree $X_{\mathrm{c}-\mathrm{XRD}}$ of polyesters were calculated by WAXD analyses.
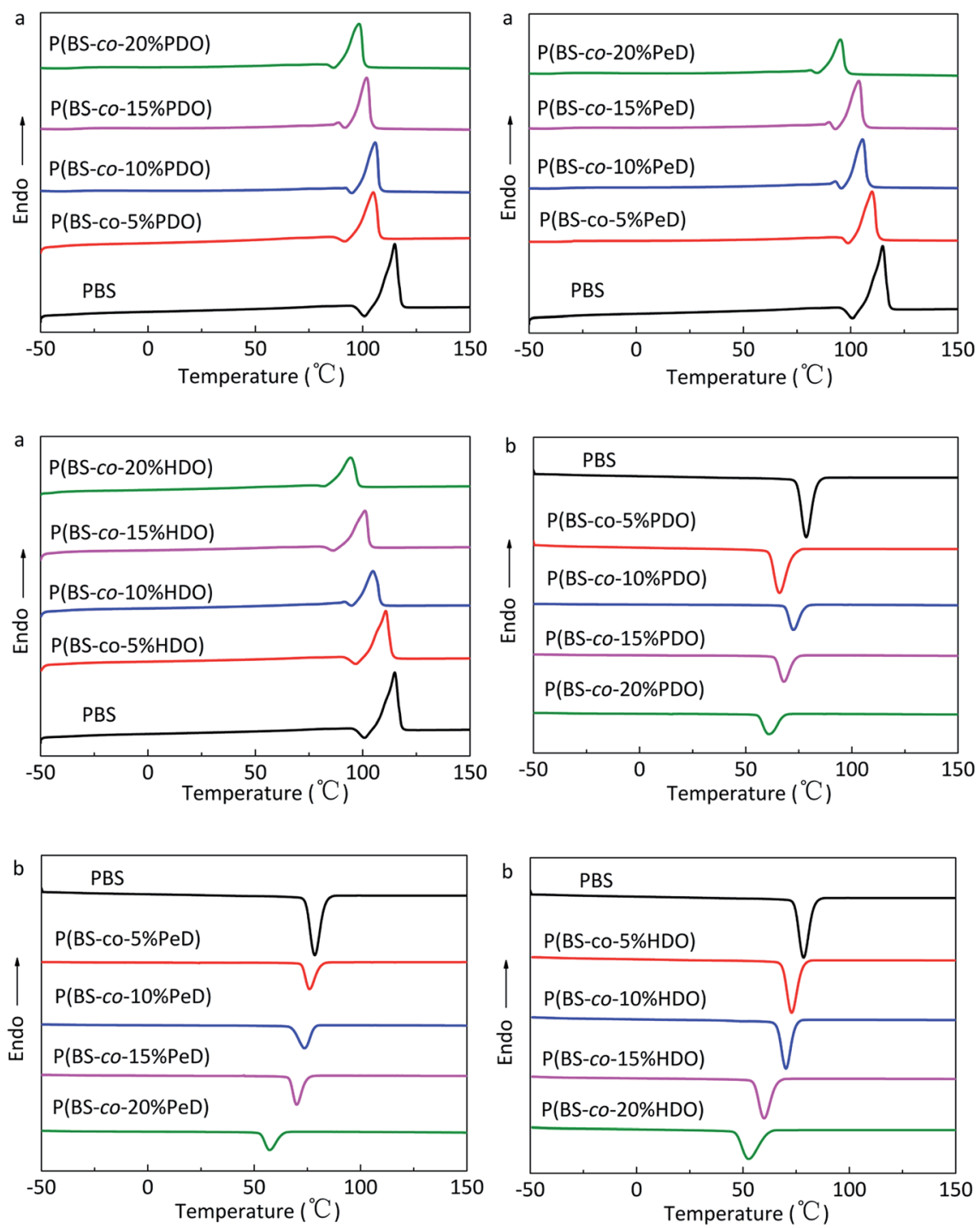

Fig. 4 DSC curves of copolyesters: (a) second heating scan at $10{ }^{\circ} \mathrm{C} \min ^{-1}$ and (b) cooling scan at $5^{\circ} \mathrm{C} \mathrm{min}-1$. 

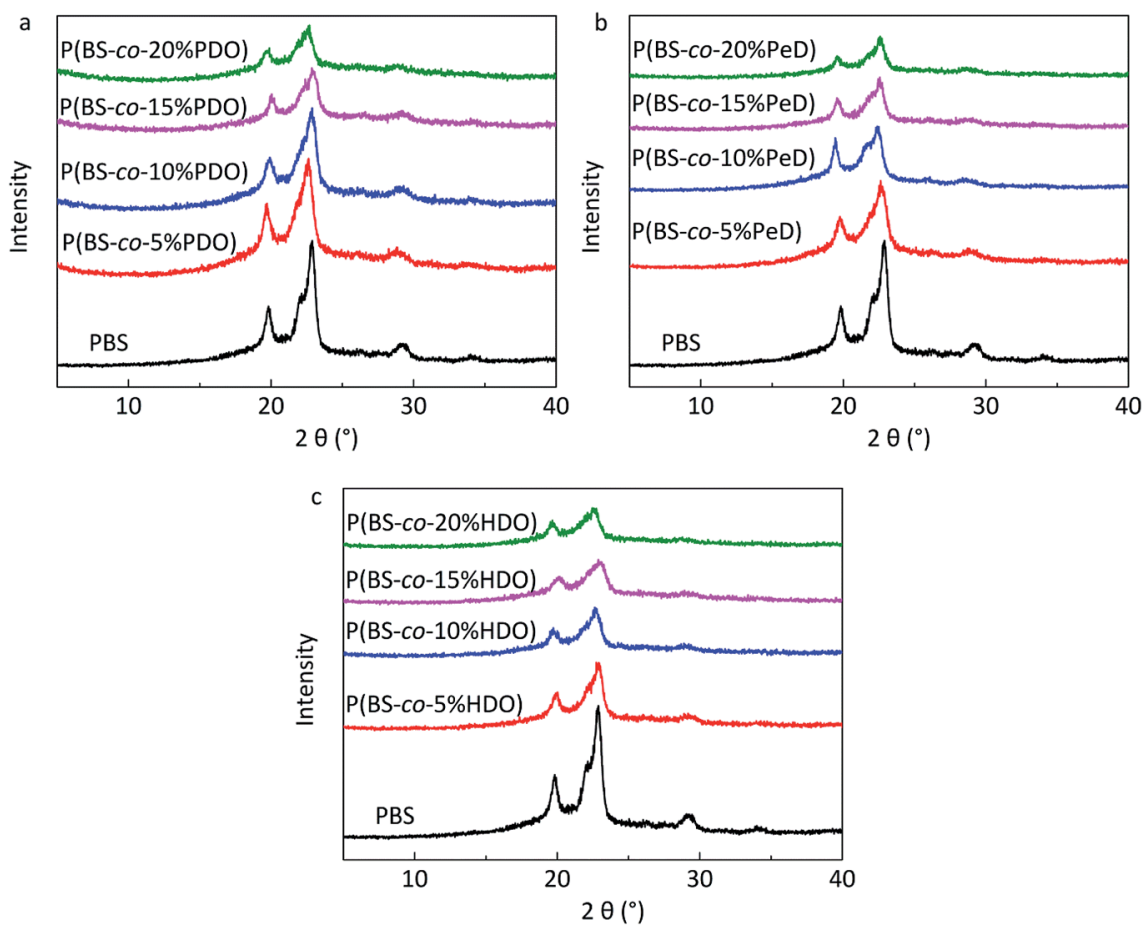

Fig. 5 WAXD profiles $\left(0.02^{\circ}\right.$ step, 50 s per step) of copolyesters: (a) P(BS-co-PDO). (b) P(BS-co-PeD). (c) P(BS-co-HDO).

the movement of the structured molecular chains requires more energy, so the neat PBS has high initial decomposition temperature. Several increased values are due to the relative higher molecular weight.

\section{LC-MS analysis}

The enzymatic degradation process was accompanied by hydrolysis. As the degradability of polyesters was dominated by their chemical structure, the degradation products of copolyesters was identified by LC-MS method. It is worth mentioning that the degradation products will not come from the ionic degradation of the LC-MS process.

From the mass-to-charge ratio $(\mathrm{m} / \mathrm{z})$ of $[\mathrm{M}-\mathrm{H}]^{-}$in Fig. 7 and the degradation products listed in Table 3 , it is notable that the $\mathrm{B}, \mathrm{S}, \mathrm{P}$ and $\mathrm{H}$ are the abbreviations of BDO, SA, PDO and HDO respectively. It was further observed that the modified PBS was
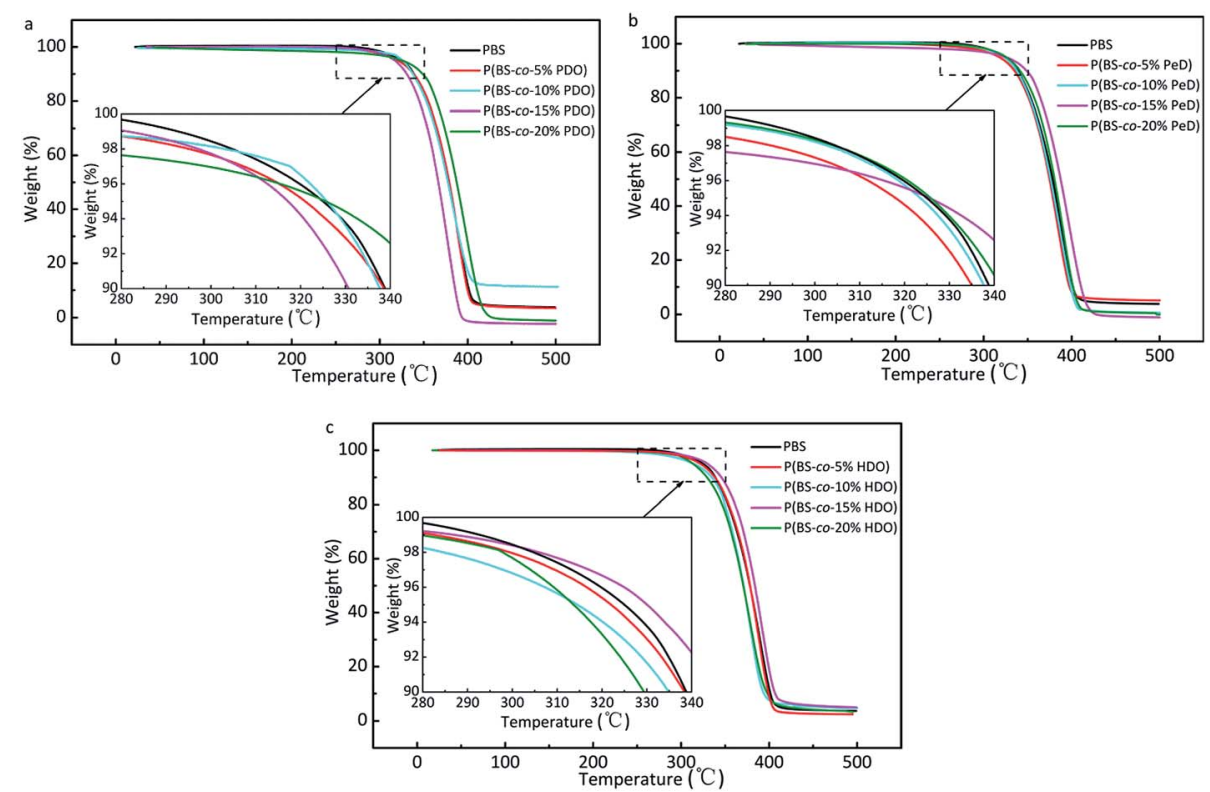

Fig. 6 TGA curves under nitrogen atmosphere $\left(10^{\circ} \mathrm{C} \mathrm{min}^{-1}\right.$ ) of copolyesters: (a) P(BS-co-PDO). (b) P(BS-co-PeD). (c) P(BS-co-HDO). 


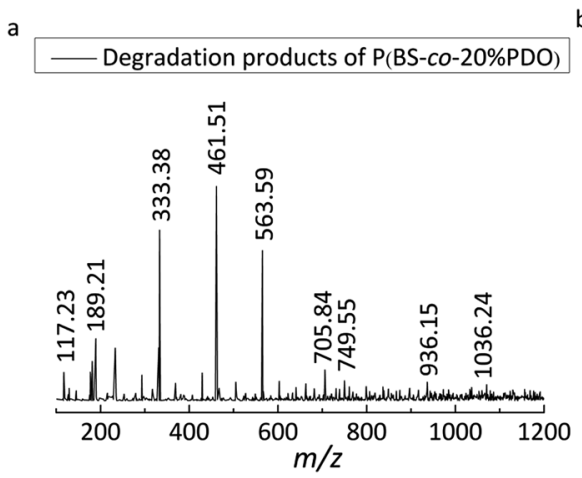

b
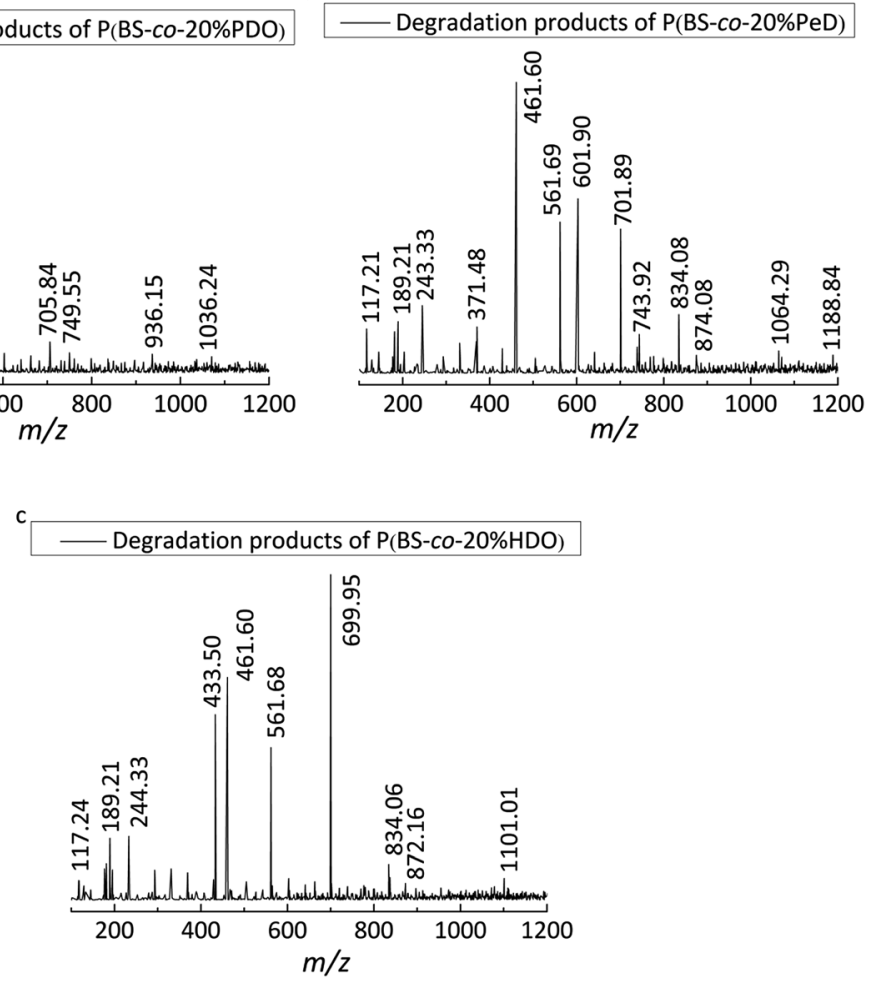

Fig. 7 LC-MS spectra (ESI-under nitrogen atmosphere) of the degradation products of polyesters: (a) P(BS-Co-20\% PDO), (b) P(BS-co-20\%PeD), (c) $\mathrm{P}(\mathrm{BS}-\mathrm{CO}-20 \% \mathrm{HDO}$ ).

degraded into different oligomers by CALB in aqueous solution after 5 days, indicating that the presence of the monomers resulted in an acceleration in the degradation process. This was certified by the detection of SA in all three copolyesters, further revealing that the SA was easily dissociated itself from the oligomers of the copolymers during the period of degradation. As a result, 13 kinds of products were obtained for $\mathrm{P}(\mathrm{BS}-\mathrm{co}-20 \% \mathrm{PeD})$, whereas 10 and 9 kinds for P(BS-co-20\%HDO) and P(BS-co-20\% $\mathrm{PDO})$, respectively, indicating that the $\mathrm{P}(\mathrm{BS}-\mathrm{co}-20 \% \mathrm{PeD})$ was more efficiently degraded by CALB. Indeed, in terms of P(BS-co-20\% $\mathrm{PeD})$, the relative abundance of higher ion peaks were attributed to $m / z 189.21$ of $\mathrm{L}$ (BS), $m / z 461.60$ of $\mathrm{L}$ (BS)(PeDS)PeD, L $(\mathrm{PeDS})_{2} \mathrm{~B}$, L (PeDS)(BS)PeD and $\mathrm{m} / z$ of $601.90 \mathrm{C}(\mathrm{BS})_{3} \mathrm{PeD}$, $\mathrm{C}(\mathrm{BS})_{2}(\mathrm{PeDS}) \mathrm{B}$, corresponding to the dimer, trimer, and pentamer with linear (L) and cyclic (C) oligomers (Table 3), suggesting that cyclization occurred during the process (Scheme 1). The use of CALB as a catalyst for polymerization under relatively mild conditions has been reported previously. ${ }^{20}$

\section{MD and alignment}

MD was carried out to explain the catalytic behavior of CALB on the copolyesters from a molecular perspective. In the computational simulation, CALB was adopted as the starting structure. CALB belongs to the serine proteases, with catalytic triad Ser105-His224-Asp187, helix $\alpha 5$ (142-146) and $\alpha 10$ (268-287), which form the accessible active site and have a high mobility to change conformation for the substrate binding. The hydrophobic residues, Leu278, Ala281 and Ile285 are located at the entrance of the active pocket to accommodate the ligand. In addition, Leu144, Val154 and Val149 are located at the top of the active pocket to stabilize the tetrahedral substrate. The CALB average structure of stable stage derived from 50 ns MD simulation, which supported the root-mean-square deviation (RMSD) of $\mathrm{C} \alpha$, represented the equilibrium state of the protein and was the monitor to evaluate the structural integrity of protein. In Fig. 8a, at the beginning of the simulation below 10 ns, the protein underwent intramolecular movement and the structure was largely adjusted to accommodate the entire water system. Therefore, the RMSD value had a large range of changes. At 10-25 ns, although the local structure of the protein remained better, relative movement occurred at the various domains of the protein, resulting in overall RMSD fluctuations. After $25 \mathrm{~ns}$, the smaller volatility indicated that the overall structure of the protein tended to be stable. Finally, the stable output conformation was used for subsequent simulation studies. With regards to the substrates, it is necessary to investigate the selection, as is well known that the acyl group can excite enzymes. Taking the mole ratio of feed materials into the consideration, we can know that the substrates include hydroxyl terminal groups. The docking procedure can get all the possible poses of substrates binding to the enzymes.

We also carried out the MD simulations of every copolyester with both wanted ligands and unwanted ligands to get the average structure of each system (Fig. 8b). The superimposition revealed that the CALB of the five systems maintained a stable state of the structure and the maximum difference occurred at 
Table 3 The degradation products of polyesters by LC-MS

\begin{tabular}{|c|c|c|c|}
\hline Polyesters $^{a}$ & {$[\mathbf{M}-\mathbf{H}]^{-}(m / z)^{b}$} & $M_{\mathrm{n}}^{c}$ & Products \\
\hline \multirow[t]{6}{*}{$\mathrm{P}(\mathrm{BS}-c o-20 \% \mathrm{PDO})$} & 117.23 & 118.23 & $\mathrm{~L}^{d} \mathrm{~S}$ \\
\hline & 189.21 & 190.21 & $\mathrm{~L}^{d} \mathrm{BS}$ \\
\hline & 461.51 & 462.51 & $\mathrm{~L}^{d} \mathrm{~S}(\mathrm{BS})_{2}$ \\
\hline & 563.59 & 564.59 & $\mathrm{~L}^{d}(\mathrm{PS})_{3} \mathrm{~B}, \mathrm{~L}^{d}(\mathrm{PS})_{2}(\mathrm{BS}) \mathrm{P}$ \\
\hline & 705.84 & 706.84 & $\mathrm{~L}^{d} \mathrm{~S}(\mathrm{BS})_{3} \mathrm{~B}$ \\
\hline & 1036.24 & 1037.24 & $\mathrm{~L}^{d}(\mathrm{BS})_{5}(\mathrm{PS}), \mathrm{L}^{d} \mathrm{~S}(\mathrm{BS})_{5} \mathrm{P}$ \\
\hline \multirow[t]{9}{*}{$\mathrm{P}(\mathrm{BS}-\mathrm{co}-20 \% \mathrm{PeD})$} & 117.21 & 118.21 & $\mathrm{~L}^{d} \mathrm{~S}$ \\
\hline & 189.21 & 190.21 & $\mathrm{~L}^{d} \mathrm{BS}$ \\
\hline & 243.33 & 244.33 & $\mathrm{C}^{e} \mathrm{BSB}$ \\
\hline & 371.48 & 372.48 & $\mathrm{C}^{e}(\mathrm{PeDS})_{2}$ \\
\hline & 461.60 & 462.60 & $\mathrm{~L}^{d}(\mathrm{BS})(\mathrm{PeDS}) \mathrm{PeD}, \mathrm{L}^{d}(\mathrm{PeDS})_{2} \mathrm{~B}, \mathrm{~L}^{d}(\mathrm{PeDS})(\mathrm{BS}) \mathrm{PeD}$ \\
\hline & 834.08 & 835.08 & $\mathrm{~L}^{d}(\mathrm{PeDS})_{4} \mathrm{~B}, \mathrm{~L}^{d}(\mathrm{PeDS})_{3}(\mathrm{BS}) \mathrm{PeD}$ \\
\hline & 874.08 & 875.08 & $\mathrm{C}^{d}(\mathrm{BS})_{4}(\mathrm{PeDS}), \mathrm{C}^{d} \mathrm{~S}(\mathrm{BS})_{4} \mathrm{PeD}$ \\
\hline & 1064.29 & 1065.29 & $\mathrm{~L}^{d}(\mathrm{BS})_{5}(\mathrm{PeDS}), \mathrm{L}^{d} \mathrm{~S}(\mathrm{BS})_{5} \mathrm{PeD}$ \\
\hline & 1188.84 & 1189.84 & $\mathrm{C}^{e}(\mathrm{PeDS})_{5}(\mathrm{BS}) \mathrm{PeD}$ \\
\hline \multirow[t]{8}{*}{$\mathrm{P}(\mathrm{BS}-c o-20 \% \mathrm{HDO})$} & 117.24 & 118.24 & $\mathrm{~L}^{d} \mathrm{~S}$ \\
\hline & 189.21 & 190.21 & $\mathrm{~L}^{d} \mathrm{BS}$ \\
\hline & 244.33 & 245.33 & $\mathrm{C}^{e} \mathrm{BSB}$ \\
\hline & 433.50 & 434.50 & $\mathrm{~L}^{d}(\mathrm{BS})_{2} \mathrm{~B}$ \\
\hline & 461.60 & 462.60 & $\mathrm{~L}^{d}(\mathrm{BS}){ }_{2} \mathrm{H}, \mathrm{L}^{d}(\mathrm{BS})(\mathrm{HS}) \mathrm{B}$ \\
\hline & 561.68 & 562.68 & $\mathrm{~L}^{d}(\mathrm{BS})_{2}(\mathrm{HS}), \mathrm{L}^{d} \mathrm{~S}(\mathrm{BS})_{2} \mathrm{H}$ \\
\hline & 699.95 & 700.95 & $\mathrm{C}^{e}(\mathrm{HS})_{3} \mathrm{H}, \mathrm{C}^{e} \mathrm{~S}(\mathrm{HS})_{3}$ \\
\hline & 834.06 & 835.06 & $\mathrm{~L}^{d}(\mathrm{BS})_{3}(\mathrm{HS}) \mathrm{H}, \mathrm{L}^{d} \mathrm{~S}(\mathrm{BS})_{3}(\mathrm{HS})$ \\
\hline
\end{tabular}

the helix $\alpha 5$, indicating that the helix $\alpha 5$, as a very mobile element, is an important channel for the ligand to entering the CALB active pocket. In order to further explore the changes in CALB structure caused by the interaction with the substrate in all systems, the averaged RMSD values of radical individual residues were calculated (Fig. 8c). The RMSD values of residues were independently less than $2 \AA$ in each system except for the residues at 140-148 around helix $\alpha 5$. Compared with CALB, it can be seen that the ligand-containing systems exhibited higher RMSD values of in the vicinity of the helix $\alpha 5$ (140-148) and helix $\alpha 10$ (265-270), elucidating that the presence of the substrate led to a response in helix $\alpha 5$, where interactions between the substrate and CALB. The order of RMSD values can be presented as follows: PDOSPDO-CALB $\approx$ BSB-CALB < PeDSPeD-CALB $\approx$ HDOSHDO-CALB, revealing that the latter two copolyesters had a higher flexibility in helix $\alpha 5$. During the

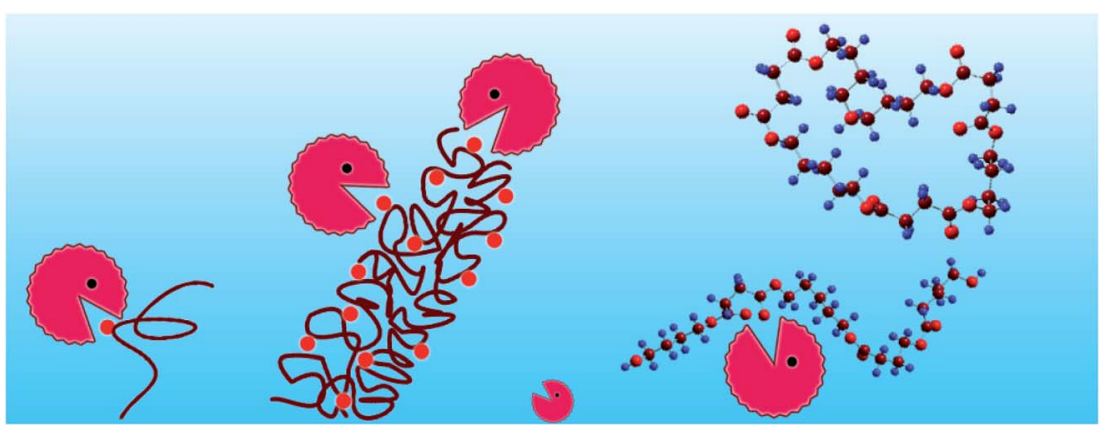

Scheme 1 The degradation of copolyester P(BS-co-PeD), the long chain of the P(BS-co-PeD) is brown, CALB is in circle with "mouth", the liner and cyclic degradation products are shown in sticks and balls. 
catalytic processes, the helix $\alpha 5$ exhibited very high flexibility and significance for CALB function. The higher the flexibility of the helix $\alpha 5$, the easier it is for the combination between CALB and the substrate. Therefore, the latter two are more likely to carry out enzymatic reactions.

\section{Molecular docking analysis}

Molecular docking studies can provide a structural insight into the interactions between compounds and the pocket residues of CALB. On the basis of the degradation results, we set about investigating the molecular interpretation of the interaction sites between ligands and receptors of binding free energies and the conformational changes during the combination process. The calculated docking results based on the molecular force field are listed in Table 4, which consists of binding free energy ( $\left.E_{\text {binding }}\right)$, intermolecular energy ( $\left.E_{\text {inter-mol }}\right)$, including van der Waals (vdW), hydrogen bonding (h bond), and desolvation potential (desolv), electrostatic energy $\left(E_{\text {elec }}\right)$, total internal energy ( $\left.E_{\text {total-internal }}\right)$, unbond energy $\left(E_{\text {unbond }}\right)$ and torsional energy $\left(E_{\text {torsional }}\right) \cdot{ }^{44}$ According to the formula, that is, $E_{\text {binding }}=$ $E_{\text {inter-mol }}+E_{\text {total-internal }}+E_{\text {torsional }}-E_{\text {unbond }}$, and $E_{\text {inter-mol }}=E_{\mathrm{vdW}}$ $+E_{\text {hbond }}+E_{\text {desolv }}+E_{\text {elec }}$, we can clearly understand the relationship between all these energies. In addition, the $E_{\text {torsional }}$ only depends on the number of torsion bond.

In Table 4, the biding free energies of PDOSPDO-CALB, PeDSPeD-CALB and HDOSHDO-CALB were successfully calculated to be $-4.61,-4.76$ and $-4.67 \mathrm{kcal} \mathrm{mol}^{-1}$, which were lower than that of CALB-BSB, $-4.04 \mathrm{kcal} \mathrm{mol}^{-1}$. In accordance with our analyses of the enzymatic degradation, the free energy of binding CALB-PeDSPeD was the lowest, indicating that the enzyme was more preferred to bind to PeDSPeD so that the copolyester $\mathrm{P}(\mathrm{BS}-\mathrm{co}-\mathrm{PeD})$ performed the best behavior during degradation.

\section{Protein-ligand interaction analysis}

As previously stated, the ligands rotate chemical bonds and expose acyl groups to the favourable residues to obtain hydrogen bonds in order to adjust and enter the acyl-binding pocket with the catalytic triad of Ser105-His224-Asp187 triumphantly further to surely implement the chemical reaction. The key hydrogen bonds were analyzed to get more details about the binding between the ligand and enzyme, shown in Fig. 9. Owing to the docking type, the hydrogen bond formed in Ser105 and His224 was fixed at $1.7 \AA$ and remained unchanged. According to the analysis, the nitrogen of His224 formed a hydrogen bond with the ligand in four complexes, PeDSPeD had the minimum value of $1.9 \AA$, whereas the maximum value of 2.5 $\AA$ was BSB. The shorter distance of hydrogen bond, the easier the catalytic reactions. Once the ligand was in contact with the active site, the tetrahedral intermediate formed, and the Thr40 and Gln106 formed an oxyanion hole and donate three hydrogen bonds to maintain the stability of the tetrahedral substrate to ensure the catalytic processes.
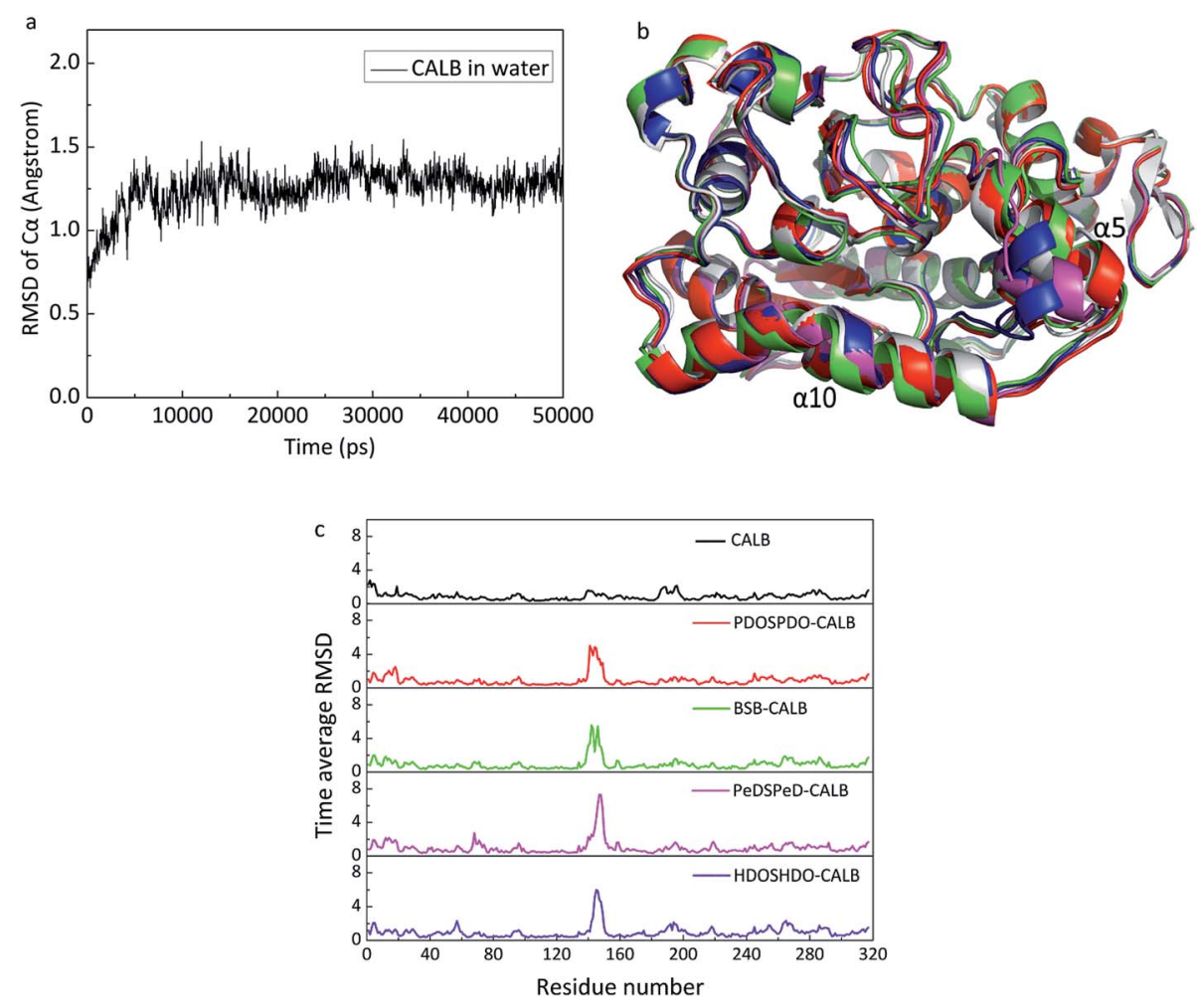

Fig. 8 (a) RMSD of initial structure of protein as a function of time, (b) superimposition of structure CALB output from MD runs of each complex, CALB output from MD simulation (green), PDOSPDO-CALB (white), BSB-CALB (magenta), PeDSPeD-CALB (blue), HDOSHDO-CALB (red), (c) time-averaged RMSD of each residue from 50 ns simulation of each system. 
Table 4 Docking results of ligand-CALB by AutoDock program ${ }^{a}$

\begin{tabular}{|c|c|c|c|c|c|c|c|}
\hline Enzyme & Ligand & $\begin{array}{l}E_{\text {binding }}{ }^{b} \\
\left(\text { kcal mol }^{-1}\right)\end{array}$ & $\begin{array}{l}E_{\text {inter-mol }} c \\
\left(\mathrm{kcal} \mathrm{mol}^{-1}\right)\end{array}$ & $\begin{array}{l}E_{\text {total-internal }}{ }^{-1} \\
\left(\text { kcal mol }^{-1}\right)\end{array}$ & $\begin{array}{l}E_{\text {torsional }}{ }^{-1} \\
\left(\mathrm{kcal} \mathrm{mol}^{-1}\right)\end{array}$ & $\begin{array}{l}E_{\mathrm{vdW}-\mathrm{hbond} \text {-desolv }}{ }^{f} \\
\left(\mathrm{kcal} \mathrm{mol}^{-1}\right)\end{array}$ & $\begin{array}{l}E_{\text {elec }}{ }^{g} \\
\left(\mathrm{kcal} \mathrm{mol}^{-1}\right)\end{array}$ \\
\hline \multirow[t]{3}{*}{ CALB } & BSB & -4.04 & -8.51 & -1.25 & 4.47 & -8.33 & -0.22 \\
\hline & PeDSPeD & -4.76 & -9.83 & -0.71 & 5.07 & -9.74 & -0.24 \\
\hline & HDOSHDO & -4.67 & -10.34 & -1.09 & 5.67 & -10.27 & -0.21 \\
\hline
\end{tabular}

${ }^{a}$ The binding results were obtained by analyzing the 200 docking poses performed by AutoDock $4.2 .{ }^{b}$ Binding free energy. ${ }^{c}$ Intermolecular energy. ${ }^{d}$ Total internal energy. ${ }^{e}$ Torsional energy. ${ }^{f}$ Energies of van der Waals, hydrogen bonding, desolvation potential. ${ }^{g}$ Electrostatic energy.

According to the analysis, Thr40 and Gln106 offered the shortest and most stable hydrogen bonds to the PeDSPeD ligand, followed by BSB, HDOSHDO, PDOSPDO in turn. Although Thr40 and Gln106 donated the shorter hydrogen bonds to ligand BSB than to HDOSHDO, the first accepted hydrogen bond from His224 was longer, which can't make the catalytic reaction run smoothly like others. Meanwhile, Thr40, Asp134 and Gln157 formed a hydrogen bond network to allow solvent accessibility. On the other hand, with the number of carbon atoms on the main chain increases, the flexibility of the substrate is improved, providing more conformations to fit the active enzyme pocket.

Thus, it is notable that the formation and stability of tetrahedral intermediate can guarantee the success of enzymeinduced catalytic reaction. In addition, the complex PeDBPeDCALB created the most stable system, which was consistent with the previous experiment and simulation, and the copolyester P(BS-co-PeD) showed excellent degradability of all.

A two-dimensional view displays a simplified representation of the ligand-receptor interactions, as depicted in Fig. 10. As discussed above, hydrogen bond interactions between the ligands and the active site indeed occurred with support from Thr40 and Gln60. Hydrophobic residues, such as Ile189, Leu278 and Ile285, were surrounding the ligand, representing the hydrophobic region around the active pock of enzyme. With the increased in carbon chain length, the hydrophobic effects of enzyme and substrate increased, leading to a more stable transition state and further facilitating the catalytic process. The hydrophobic effects of the four complexes was in the orders of PDOSPDO-CALB $\approx$ BSB-CALB $<$ PeDSPeD-CALB $\approx$ HDOSHDO-CALB, which was in accordance with the experimental results. At the same time, the solvent entered into the
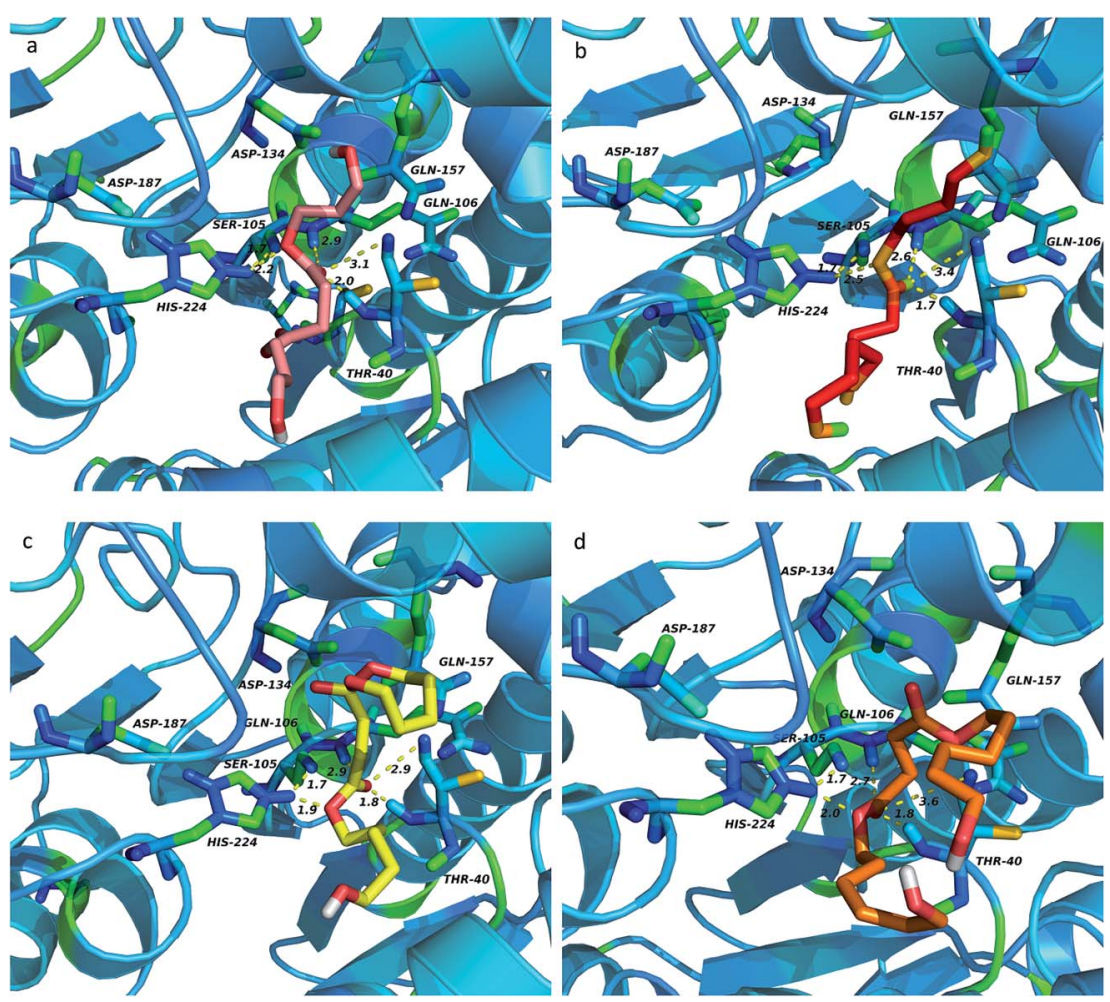

Fig. 9 Key hydrogen bonds analysis of ligands top-ranking conformations binding to enzyme: (a) PDOSPDO, (b) BSB, (c) PeDSPeD, (d) HDOSHDO. The hydrogen bonds were depicted in yellow dot lines. 

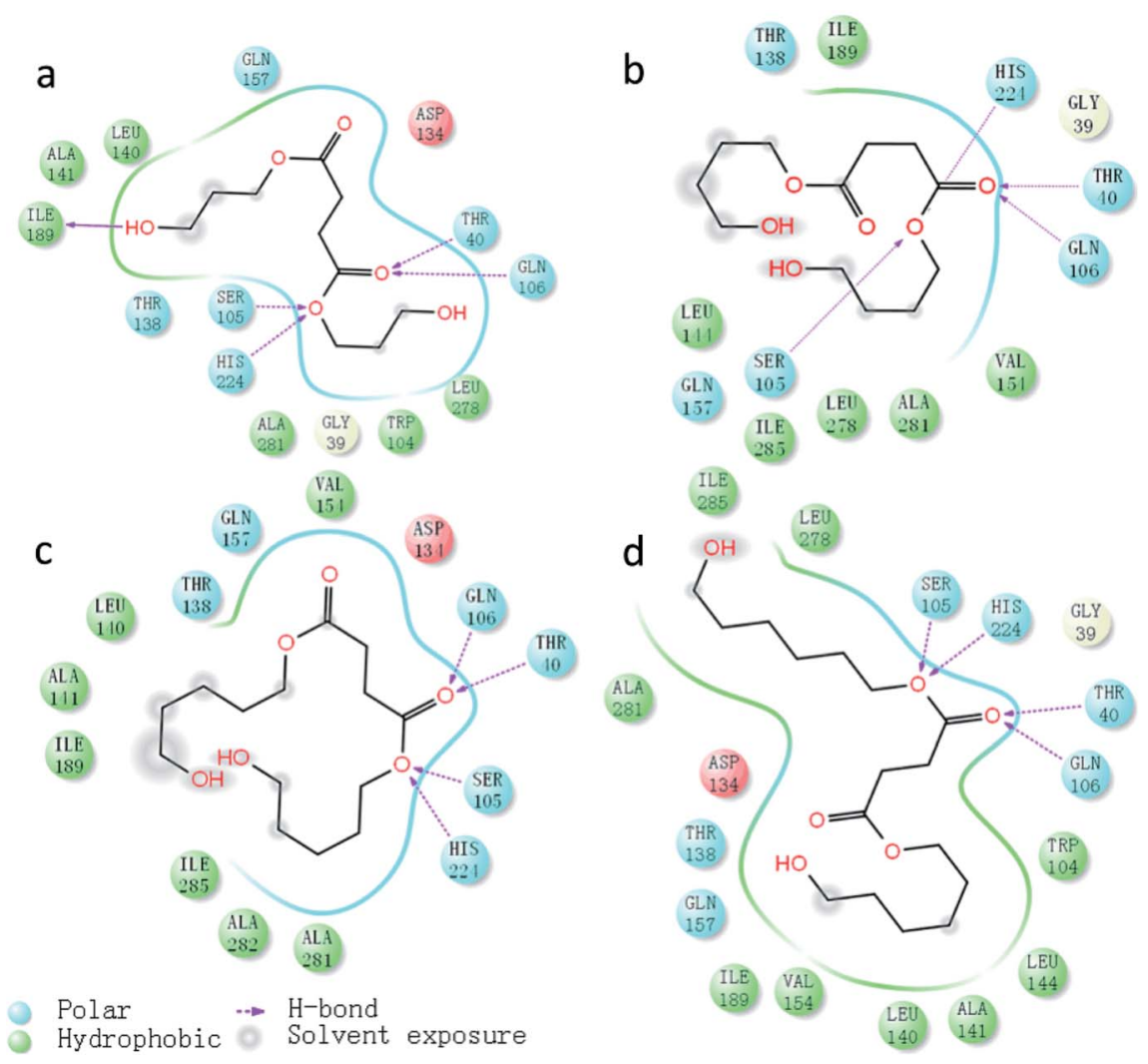

Fig. 10 Two-dimensional view of ligand-receptor interactions, hydrogen bonds were in purple dash line: (a) PDOSPDO-CALB, (b) BSB-CALB, (c) PeDSPeD-CALB, (d) HDOSHDO-CALB.

active pocket through a hydrogen bond network formed by Thr40, Asp134 and Gln157, followed by an exposed ligand, thus facilitating the reaction take place smoothly.

\section{Conclusions}

In this study, we have introduced the different third monomers to alter the degradability of pure PBS. Molecular simulation was performed in order to provide a molecular explanation to the interaction of the ligand-protein complex. The experiment results showed that the order of degradation rate was $\mathrm{P}$ (BS- $\mathrm{co}$ $\mathrm{PeD})>\mathrm{P}(\mathrm{BS}-c o-\mathrm{HDO})>\mathrm{P}(\mathrm{BS}-c o$-PDO $)>\mathrm{PBS}$, indicating that all the copolyesters modified by the short chain monomers were more easily degraded than pure PBS due to the irregular chain segment breaking the spiral structure of PBS, thus providing more amorphous region for CALB to interact.

Combined with molecular simulations, MD revealed that the overall conformation of CALB was stable in water. The enzyme, adhering to the substrates PeD and HDO, exhibited a higher flexibility in helix $\alpha 5$ that can make CALB more easily bind to the substrate, thereby facilitating the enzymatic reaction and resulting in better degradation performance. As for molecular docking, it can be seen that PeDSPeD-CALB had the lowest free energy of binding, and presented the outstanding degradability for the copolyester P(BS-co-PeD). Moreover, the shortest and strongest hydrogen bonds of PeDSPeD-CALB around the active site pocket also showed a the tight combination, indicating that the presence of PeD did accelerate the degradation of PBS. All the molecular simulations match well with the experimental results and provide another potential way to get insight into the degradation mechanism of polyesters.

\section{Conflicts of interest}

There are no conflicts to declare.

\section{Acknowledgements}

We acknowledge the financial support from the Research Fund at the People's Government of Shaanxi Province of China (2016CG-10), and the research is funded by Shaanxi University of Science and Technology (BJ15-21).

\section{Notes and references}

1 D. Lithner, A. Larsson and G. Dave, Sci. Total Environ., 2011, 409, 3309-3324.

2 E. H. Chelsea, M. Rochman, B. T. Hentschel and S. Kaye, Environ. Sci. Technol., 2013, 47, 1646-1654.

3 C. Vilela, A. F. Sousa, A. C. Fonseca, A. C. Serra, J. F. J. Coelho, C. S. R. Freirea and A. J. D. Silvestrea, Polym. Chem., 2014, 5, 3119-3141.

4 Y. Sasanuma, Y. Nonaka and Y. Yamaguchi, Polymer, 2013, 56, 327-339. 
5 M. A. Hillmyer and W. B. Tolman, Acc. Chem. Res., 2014, 47, 2390-2396.

6 Z. Wu, K. Zheng, J. Zhang, T. Tang, H. Guo, A. R. Boccaccini and J. Wei, J. Mater. Chem. B, 2016, 4, 7974-7988.

7 M. Zhang, M. L. Ding, T. Zhang and J. M. Yang, Chem. J. Chin. Univ., 2010, 31, 612-615.

8 J. Wang, L. Zheng, C. Li, W. Zhu, D. Zhang and G. Guan, Ind. Eng. Chem. Res., 2012, 51, 10785-10792.

9 M. Gigli, M. Govoni, N. Lotti and E. D. Giordano, RSC Adv., 2014, 4, 32965-32976.

10 G. Totaro, L. Sisti, A. Celli, H. Askanian, V. Verney and F. Leroux, RSC Adv., 2016, 6, 4780-4791.

11 L. Genovese, N. Lotti, M. Gazzano, V. Siracusa, M. Dalla and A. Munari, Polym. Degrad. Stab., 2016, 132, 191-201.

12 V. Siracusa, N. Lotti, A. Munari and M. Dalla Rosa, Polym. Degrad. Stab., 2015, 119, 35-45.

13 A. Jäger, D. Gromadzki, E. Jäger, F. C. Giacomelli, A. Kozlowska, L. Kobera, J. Brus, B. Ř́hová, M. El Fray, K. Ulbrich and P. Štěpánek, Soft Matter, 2012, 8, 4343-4354.

14 M. Gigli, M. Fabbri, N. Lotti, R. Gamberini, B. Rimini and A. Munari, Eur. Polym. J., 2016, 75, 431-460.

15 J. Wang, L. Zheng, C. Li, W. Zhu, D. Zhang, G. Guan and Y. Xiao, Ind. Eng. Chem. Res., 2012, 51, 10785-10792.

16 M. Gigli, A. Negroni, M. Soccio, G. Zanaroli, N. Lotti, F. Fava and A. Munari, Green Chem., 2012, 14, 2885-2893.

17 H. Maeda, Y. Yamagata, K. Abe, F. Hasegawa, M. Machida, R. Ishioka, K. Gomi and T. Nakajima, Appl. Microbiol. Biotechnol., 2005, 67, 778-788.

18 M. Gigli, A. Negroni, M. Soccio, G. Zanaroli, N. Lotti, F. Fava and A. Munari, Polym. Degrad. Stab., 2013, 98, 934-942.

19 M. Gigli, A. Negroni, G. Zanaroli, N. Lotti, F. Fava and A. Munari, React. Funct. Polym., 2013, 73, 764-771.

20 M. Suhartini, H. Mitomo, F. Yoshii, N. Nagasawa and T. Kume, J. Polym. Environ., 2001, 9, 163-171.

21 Y. Jiang, A. J. J. Woortman, G. O. R. A. van Ekenstein and K. Loos, Biomolecules, 2013, 3, 461-480.

22 B. Réjasse, T. BessonEn, M.-D. Legoy and S. Lamare, Org. Biomol. Chem., 2006, 4, 3703-3707.

23 J. Uppenberg, M. T. Hansen, S. Patkar and T. A. Jones, Structure, 1994, 2, 293-308.

24 J. Uppenberg, N. öhrner, M. Norin, K. Hult, G. J. Kleywegt, S. Patkar, V. Waagen, T. Anthonsen and T. A. Jones, Biochemistry, 1995, 34, 16838-16851.

25 M. Skjøt, L. De Maria, R. Chatterjee, A. Svendsen, S. A. Patkar, P. R. Østergaard and J. Brask, ChemBioChem, 2009, 10, 520-527.
26 F. van Rantwijk, F. Secundo and R. A. Sheldon, Green Chem., 2006, 8, 282-286.

27 T. Zisis, P. L. Freddolino, P. Turunen, M. C. F. van Teeseling, A. E. Rowan and K. G. Blank, Biochemistry, 2015, 54, 59695979.

28 M. Happe, P. Grand, S. Farquet, S. Aeby, J.-C. Héritier, F. Corthay, E. Mabillard, R. Marti, E. Vanoli, A.-F. Grogg, S. Nussbaum, A. Roduit, F. Tièche, S. Salem, C. Constantin, E. Schmitt, S. Zahno, C. Ellert, A. Habib, J. Wyss and F. Fischer, Green Chem., 2012, 14, 2337-2345.

29 Q. Wu, P. Soni and M. T. Reetz, J. Am. Chem. Soc., 2013, 135, 1872-1881.

30 S. Jung, J. Kim and S. Park, RSC Adv., 2013, 3, 2590-2594.

31 Z. Gan, H. Abe and Y. Doi, Biomacromolecules, 2001, 2, 313321.

32 F. Jbilou, C. Joly, S. Galland, L. Belard, V. Desjardin, R. Bayard, P. Dole and P. Degraeve, Polym. Test., 2013, 32, 1565-1575.

33 J. C. Hermann, R. Marti-Arbona, A. A. Fedorov, E. Fedorov, S. C. Almo, B. K. Shoichet and F. M. Raushel, Nature, 2007, 448, 775-779.

34 H. Farrokhpour, V. Pakatchian, A. Hajipour, F. Abyar, A. Najafi Chermahini and F. Fakhari, $R S C A d v ., 2015,5$, 68829-68838.

35 J. Qin, M. Zhang, C. Zhang, C. Li, Y. Zhang, J. Song, H. M. Asif Javed and J. Qiu, RSC Adv., 2016, 6, 17896-17905.

36 D. S. Goodsell and A. J. Olson, Proteins: Struct., Funct., Genet., 1990, 8, 195-202.

37 B. A. Tejo, A. B. Salleh and J. Pleiss, J. Mol. Model., 2004, 10, 358-366.

38 E. Krieger, G. Koraimann and G. Vriend, Proteins: Struct., Funct., Genet., 2002, 47, 393-402.

39 T. Darden, D. York and L. Pedersen, J. Chem. Phys., 1993, 98, 10089-10092.

40 G. M. Morris, R. Huey, W. Lindstrom, M. F. Sanner, R. K. Belew, D. S. Goodsell and A. J. Olson, J. Comput. Chem., 2009, 30, 2785-2791.

41 G. M. Morris, D. S. Goodsell, R. S. Halliday, R. Huey, W. E. Hart, R. K. Belew and A. J. Olson, J. Comput. Chem., 1998, 19, 1639-1662.

42 J.-L. Stigliani, V. Bernardes-Génisson, J. Bernadou and G. Pratviel, Org. Biomol. Chem., 2012, 10, 6341-6349.

43 W. L. DeLano, PyMOL: An Open-Source Molecular Graphics Tool, DeLano Scientific, San Carlos, CA, USA, 2002.

44 X. Hou, J. Du, J. Zhang, L. Du, H. Fang and M. Li, J. Chem. Inf. Model., 2012, 53, 188-200. 